DOI: 10.17805/zpu.2015.2.37

\title{
Модель организации самостоятельной работы будущих педагогов на основе информационно-коммуникационных технологий
}

\author{
Ю. В. КРАСАВИНА \\ (ИЖЕВСКИЙ ГОСУДАРСТВЕННЫЙ ТЕХНИЧЕСКИЙ УНИВЕРСИТЕТ \\ ИМ. М. Т. КАЛАШНИКОВА)
}

В статье описана модель организации самостоятельной работы студентов бакалавриата - будущих педагогов профессионального обучения в условиях компетентностного подхода. Модель реализована в Ижевском государственном техническом университете им. М. Т. Калашникова на примере дисциплины «Английский язык».

Модель учитывает важные для будущих педагогов компетенции: профессиональную иноязычную и профессиональную информационно-коммуникационную (ИКТ). Повышение эффективности организации самостоятельной работы студентов - будущих педагогов по дисциплине «Английский язык» предлагается достичь за счет использования метода проектов в электронной среде. Выполнение данных проектов включает работу с иноязычными текстами профессиональной направленности, закрепление знаний по одной из основных дисциплин данного профиля, а также изучение основ проектирования в электронной среде. Так реализуется принцип синергизма, формируются важные профессиональные компетенции, повышается профессиональная готовность будущего специалиста.

Модель представлена четырьмя взаимосвязанными блоками: целевым, проектным, организационным и диагностико-результативным. Для оценки эффективности реализации модели выделены структурные составляющие основных формируемых компетенций. В структуре профессиональной иноязычной компетенции сформулированы компетенции, формирующие ее экзистенциальный, коммуникативный, социальный и оценочный компоненты. Профессиональная ИКТ-компетенция, связанная с навыками проектирования в электронной среде Moodle, представлена в виде совокупности компетенций, сгруппированных по следующим видам навыков: базовые навыки работы, навыки представления материала и навыки составления тестовых заданий в электронной среде Moodle. B качестве прикладной части приведенной модели разработан учебно-методический комплекс (УМК), представляющий собой дистанционный курс в среде Moodle.

Представленная модель организации самостоятельной работы студентов ориентирована не только на развитие профессиональных иноязычной и ИКТ-компетенций, но и на формирование психолого-педагогических и методических компетенций, важных для профессиональной деятельности будущих педагогов, что, несомненно, увеличивает эффективность предложенной модели.

Ключевые слова: самостоятельная работа студентов, профессиональная иноязычная компетенция, профессиональная ИКТ-компетенция, педагог профессионального образования, информационно-коммуникационные технологии.

\section{BВЕАЕНИЕ}

$\Phi$ едеральные государственные образовательные стандарты (ФГОС) высшего профессионального образования ориентированы на перераспределение учебной нагрузки в сторону увеличения часов, отводимых на самостоятельную работу студентов (СРС). Это обусловливает значительное влияние ее эффективности на качество учебного процесса и ставит перед преподавателями вузов задачи планирования и грамотного использования отводимых на СРС часов, разработки новых эффективных моделей ее организации.

Целью данной статьи является разработка эффективной модели организации самостоятельной работы студентов - будущих педагогов, обеспечивающей формирование важных профессиональных компетенций. 
Модель организации самостоятельной работы будущих педагогов, рассмотренная в данной статье, была реализована в Ижевском государственном техническом университете им. М. Т. Калашникова. Она основана на использовании метода проектов и ИКТ. Продуктом проектной деятельности студентов стал электронный курс "Learning about Famous Scientists" (гостевой доступ по ссылке: http://e-learning.istu.ru/ course/view.php?id=128; пароль: "scientists"). Также результатом самостоятельной работы студентов стала коллективная научная работа, с которой студенты приняли участие во Всероссийском конкурсе на лучшую студенческую научную работу за 2013/2014 учебный год, организованном Фондом развития отечественного образования (г. Сочи).

\section{ОПИСАНИЕ МОАЕАИ ОРГАНИЗАЦИИ САМОСТОЯТЕАЬНОЙ РАБОТЫ}

Анализ ФГОС по направлению подготовки «Профессиональное обучение (по отраслям)», а также других нормативных документов показал, что важными для современных педагогов являются профессиональные иноязычная и информачионно-коммуникачионная (ИКТ) компетенции (Красавина, 2013).

Понятие «профессиональная ИКТ-компетентность» введено в Проекте профессионального стандарта педагога и трактуется как «квалифицированное использование общераспространенных в данной профессиональной области в развитых странах средств ИКТ при решении профессиональных задач» (Профессиональный стандарт педагога (проект), 2013: Электр. ресурс). ИКТ-компетениия также указывается среди ключевых компетенций педагога в нормативных документах Евросоюза (Кеу сотреtences ..., 2010: Электр. ресурс). С ней у будущих педагогов профессионального обучения прямо или косвенно связан ряд представленных в ФГОС компетенций: способность самостоятельно работать на компьютере; готовность к организации образовательного процесса с применением интерактивных технологий и др. (Федеральный государственный образовательный ..., 2009: Электр. ресурс).

Предлагаемая нами модель организации СРС в рамках дисциплины «Английский язык», в дополнение к профессиональной иноязычной компетенции, учитывающая и данные компетенции, и возможности их формирования на основе информационнокоммуникационных технологий и метода проектов, включает четыре блока: целевой, проектный, организационный и диагностико-результативный.

Целевой блок определяет цель и основные задачи СРС. Целью работы является повышение эффективности СРС за счет использования средств ИКТ и метода проектов, а основными задачами - развитие профессионально важных для будущих педагогов иноязычной и ИКТ-компетенций, существенно расширяющих возможности профессиональных коммуникаций. В качестве теоретико-методологической базы представлены дидактика и нормативно-правовые документы в сфере образования: Федеральный закон Российской Федерации от 29 декабря 2012 г. № 273-Ф3 «Об образовании в Российской Федерации» и др. (см.: Федеральный закон Российской Федерации ..., 2012: Электр. ресурс; Профессиональный стандарт педагога (проект), 2013: Электр. ресурс; Постановление Правительства ..., 2011: Электр. ресурс; Постановление Правительства ..., 2000: Электр. ресурс; также некоторые нормативные документы Евросоюза: Key competences ..., 2010: Электр. ресурс).

Аидактический аспект отражает цели, виды, формы и методы СРС, организованной посредством ИКТ, а также роль и функции преподавателя в ее управлении. Что касается нормативных документов, то они позволяют учесть стратегические направления развития в сфере образования на ближайшие годы, предусматривающие, в том 
числе, академическую мобильность студентов и преподавателей; использование информационных коммуникационных технологий и электронных образовательных ресурсов; общие требования к реализации образовательных программ, включая использование электронного обучения и дистанционных образовательных технологий, и др.

Проектный блок устанавливает основные принципы проектирования:

- профессиональной направленности - реализуется путем совершенствования навыков работы студентов с текстами профессиональной направленности на английском языке;

- междисииплинарности - реализуется посредством выбора тем проектов на английском языке с учетом содержания дисциплины «История физики для будущих педагогов профессионального обучения», входящей в структуру учебного плана данного направления подготовки;

- студентоцентрированности - реализуется за счет учета характера мотивации (на основе методики К. Замфир в модификации А. Реана) и особенностей мышления современного студента, ориентированного на визуальную информацию; познавательных интересов студента (за счет возможности выбора темы индивидуального проекта);

- модульности - определяет модульную структуру электронного обучающего курса;

- самоорганизации - предполагает контроль студента за собственными действиями;

- интерактивности - реализуется путем включения в учебный процесс дискуссий и обсуждений, в том числе в форме проведения форумов в электронной среде.

Аля выявления структуры профессионально-важных компетенций, отбора содержания компетентностно-ориентированной подготовки, оценки качества разработанной обучающей среды использовался метод групповых экспертных оценок (Черепанов, 1988; Шихова, 2012; Шихова, Шихов, 2013). Процедура его реализации предполагает оценку компетентности экспертов, расчет численности экспертной группы и достоверности полученных результатов. В качестве экспертов были привлечены наиболее квалифицированные преподаватели кафедр английского языка и профессиональной педагогики Ижевского государственного технического университета им. М. Т. Калашникова.

Структура профессиональной иноязычной компетенции включает экзистенщиальную, объектную (коммуникативную), сочиальную и оченочную составляющие. В экзистенциальной составляющей выделены два компонента: экзистенциальный (осознание нужности изучения иностранного языка, умение мотивировать себя на изучение иностранного языка) и познавательный (анализ информации на иностранном языке, навыки извлечения информации). Объектная составляющая представлена речевым (навыки и умения аудирования, чтения, письма и говорения) и компенсаторным компонентами. Социальная составляющая - это знание профессиональных установок, правил иноязычного общения и умение высказать свою точку зрения по темам, связанным с будущей профессией на иностранном языке. Оценочная составляющая знание критериев оценивания учебного материала по специальности на иностранном языке.

Профессиональная ИКТ-компетенция в рассматриваемой модели связана с навыкам проектирования образовательных ресурсов в электронной среде Moodle. B eе структуре выделены базовые навыки работы, навыки представления информации в электронном виде и навыки составления тестовых заданий. 
Результатом практической реализации представленных принципов и содержания компетентносто-ориентированной подготовки является создание учебно-методического комплекса (УМК) в виде дистанционного курса. Аанный курс предусматривает разработку студентами в рамках коллективного проекта информативно-обучающей мини-энциклопедии в среде Moodle на английском языке "Learning about Famous Scientists", которая, в свою очередь, может быть использована для самостоятельной работы студентов младших курсов.

Выполнение проекта производится в три этапа, соответствующих модульной структуре УМК. Основной этап представлен учебным и проектно-исследовательским модулями. Учебный модуль включает два раздела. Первый направлен на увеличение словарного запаса и совершенствование навыков иноязычной речевой деятельности, второй - на формирование навыков проектирования в электронной среде.

Проектно-исследовательский модуль реализует поэтапное формирование продукта проектной деятельности - разработку информационного сообщения с последующим контролем усвоения материала на иностранном языке в электронной среде. Результатом работы каждого студента на данном этапе должна стать разработка по теме "Learning about Famous Scientists" в среде Moodle, которая включает реферат, тест на усвоение основной информации, презентацию и доклад о жизни и деятельности одного из ученых данной области науки. По результатам выполнения проекта также может быть написана коллективная научная работа, которая отражает основные требования к современным электронным ресурсам, результаты анализа эффективности сайтов по данной тематике, а также содержит описание создаваемого электронного ресурса. Студентам, владеющим английским языком на уровне выше среднего, предлагается перевести данную работу на английский язык.

Заключительный этап представлен контрольно-оченочным модулем, который предусматривает обсуждение и оценку качества разработки как самим студентом-исполнителем, так и другими участниками проекта.

В организачионном блоке модели отражены условия организации самостоятельной работы и используемые при этом методы: проблемного обучения, интерактивные, групповых әкспертных оценок. Предусмотрены заочная и очно-заочная форма организации СРС. На выполнение всех модулей предусмотрено не более трех месяцев.

Аиагностико-результативный блок модели предполагает оценку уровня сформированности профессиональных и общекультурных компетенций посредством наблюдения, анкетирования, анализа выполненной работы. При оценивании учитываются такие критерии, как сроки выполнения работы, соответствие содержания заявленной теме, глубина проработки темы и качество оформления.

\section{ЗАКАЮЧЕНИЕ}

Представленная модель организации самостоятельной работы студентов ориентирована не только на развитие профессиональных иноязычной и ИКТ-компетенций, но и на формирование психолого-педагогических и методических компетенций, важных для профессиональной деятельности будущих педагогов, что, несомненно, увеличивает эффективность предложенной модели.

\section{СПИСОК АИТЕРАТУРЫ}

Красавина, Ю. В. (2013) О роли информационных и коммуникационных технологий в подготовке студентов - будущих педагогов // Современные фундаментальные и прикладные исследования. № 4 (11). С. 31-34. 
Постановление Правительства Российской Федерации от 4 октября 2000 г. № 751 г. Москва «О национальной доктрине образования в Российской Федерации» (2000) [Электр. ресурс]// Российская газета. 11 октября. URL: http://rg.ru/2000/10/11/doktrina-dok.html [архивировано в WebCite] (дата обращения: 29.06.2014).

Постановление Правительства Российской Федерации от 7 февраля 2011 г. № 61 г. Москва «О Федеральной целевой программе развития образования на 2011-2015 годы» (2011) [Электр. ресурс] // Российская газета. 9 марта. URL: http://rg.ru/2011/03/09/obrazovanie-site-dok.html [архивировано в WebCite] (дата обращения: 29.06.2014).

Профессиональный стандарт педагога (проект) (2013) [Электр. ресурс]// Министерство образования и науки Российской Федерации. 15 февраля. URL: http://минобрнауки.рф/документы/3071 [архивировано в Archive.Today] (дата обращения: 29.06.2014).

Федеральный государственный образовательный стандарт высшего профессионального образования по направлению подготовки 051000 «Профессиональное обучение (по отраслям)» (2009) [Электр. ресурс]// Российское образование. Федеральный портал. URL: http://edu.ru/ $\mathrm{db}-\mathrm{mon} / \mathrm{mo} / \mathrm{Data} / \mathrm{d}$ 09/prm781-1.pdf [архивировано в WebCite] (дата обращения: 29.06.2014).

Федеральный закон Российской Федерации от 29 декабря 2012 г. № 273-Ф3 «Об образовании в Российской Федерации» (2012) [Электр. ресурс]// Российская газета. № 5976. 31 декабpя. URL: http://rg.ru/2012/12/30/obrazovanie-dok.html [архивировано в WebCite] (дата обращения: 29.06.2014).

Черепанов, В. С. (1988) Экспертные методы в педагогике : учеб. пособие. Пермь : ПГПИ. 83 с.

Шихова, О. Ф. (2012) Модель проектирования многоуровневых оценочных средств для диагностики компетенций студентов в техническом вузе // Образование и наука. № 2. С. 23-31.

Шихова, О. Ф., Шихов, Ю. А. (2013) Квалиметрический подход к диагностике компетенций выпускников высшей школы // Образование и наука. № 4. С. 40-57.

Key competences for adult learning professionals: Contribution to the development of a reference framework of key competences for adult learning professionals. Final report (2010) / B. J. Buiskool, S. D. Broek, J. A. van Lakerveld, G. K. Zarifis, M. Osborne [Электр. pecypc] // Grundtvig International Network of Course Organisers. URL: http://ginconet.eu/sites/default/files/Key_Competences_For_Adult_Educators.pdf [архивировано в WebCite] (дата обращения: 29.06.2014).

Аата поступления: 09.07.2014 г.

\section{INFORMATION AND COMMUNICATION TECHNOLOGIES IN ORGANIZING EDUCATION MAJORS' SELF-STUDY \\ YU. V. KRASAVINA}

(M. T. KALASHNIKOV IZHEVSK STATE TECHNICAL UNIVERSITY)

This paper introduces a model for organizing bachelor students' self-study within the framework of the competency-based approach. The target students are majoring in teaching general technical disciplines. This model has been implemented at M.T. Kalashnikov Izhevsk State Technical University in teaching English for specific purposes. It includes four integrated units describing self-study objectives, design, organizing and evaluation process.

Students' self-study experience aims to develop the competences that are vital for future teachers: professional English competency and professional information and communication (ICT) competency. The article also introduces dictionaries for ICT and professional English competencies that can be used to assess the self-study efficiency. Professional English competency consists of existential, communicative, social and evaluative components. Professional ICT competency is related to skills a teacher needs to create an e-course. Thus, ICT-competency is viewed here as a set of competencies that are classified as basic ICT skills, information presentation skills and evaluation design skills in MOODLE.

In order to put the developed model into practice and organize students' self-study outside the classroom, an e-course for learning English for professional purposes was created in MOODLE. Introducing e-learning into English courses for future teachers will be more effective if it is based on 
the projects method. To ensure higher efficiency, we have applied here the principle of cross-curricular teaching, which allows students to gain knowledge and skills in more than one academic discipline.

While working on their projects in MOODLE, students not only acquire professional English competency but also learn how to create e-courses on their own and strengthen their knowledge in the topic of their research (in our case, History of physics). Thus, by implementing the synergy principle the suggested model helps develop students' professional competence and better prepare them for the professional world.

The suggested model of organizing students' self-study also helps build psychological, pedagogical and methodical competencies which definitely contribute to its efficacy.

Keywords: students' self-study, professional English competency, professional ICT-competency, vocational educator, information and communication technologies.

\section{REFERENCES}

Krasavina, Yu. V. (2013) O roli informatsionnykh i kommunikatsionnykh tekhnologii v podgotovke studentov - budushchikh pedagogov [The role of information and communication technologies in training students - education majors]. Sovremennye fundamental'nye $i$ prikladnye issledovaniia, no. 4 (11), pp. 31-34. (In Russ.).

Postanovlenie Pravitel'stva Rossiiskoi Federatsii ot 4 oktiabria 2000 g. № 751 g. Moskva «O natsional'noi doktrine obrazovaniia v Rossiiskoi Federatsii» [Decree of the Government of the Russian Federation under date of October 4, 2000 No. 751, Moscow "On the National Doctrine of Education in the Russian Federation"]. (2000) Rossiiskaia gazeta. October 11. [online] Available at: http:// rg.ru/2000/10/11/doktrina-dok.html [archived in WebCite] (accessed 29.06.2014). (In Russ.).

Postanovlenie Pravitel'stva Rossiiskoi Federatsii ot 7 fevralia 2011 g. № 61 g. Moskva «O Federal'noi tselevoi programme razvitiia obrazovaniia na 2011-2015 gody» [Decree of the Government of the Russian Federation under date of February 7, 2011 No. 61, Moscow "On the Federal Target Program on Education Development for the years 2011-2015"]. (2011) Rossiiskaia gazeta. March 9. [online] Available at: http://rg.ru/2011/03/09/obrazovanie-site-dok.html [archived in WebCite] (accessed 29.06.2014). (In Russ.).

Professional'nyi standart pedagoga (proekt) [Professional standard for educators (draft)]. (2013) Ministerstvo obrazovaniia $i$ nauki Rossiiskoi Federatsii [Ministry of Education and Science of the Russian Federation]. February 15. [online] Available at: http://минобрнауки.рф/документы/3071 [archived in Archive.Today] (accessed 29.06.2014). (In Russ.).

Federal'nyi gosudarstvennyi obrazovatel'nyi standart vysshego professional'nogo obrazovaniia po napravleniiu podgotovki 051000 «Professional'noe obuchenie (po otrasliam)»[Federal State Education Standard of Higher Professional Education for 051000 specialty area "Professional education (by discipline)"]. (2009) Rossiiskoe obrazovanie. Federal' nyi portal [online] Available at http://edu.ru/db-mon/mo/Data/d_09/prm781-1.pdf [archived in WebCite] (accessed 29.06.2014). (In Russ.).

Federal'nyi zakon Rossiiskoi Federatsii ot 29 dekabria 2012 g. № 273-FZ «Ob obrazovanii v Rossiiskoi Federatsii» [Federal Law of the Russian Federation under date of December 29, 2012 No. 273-FZ "On Education in the Russian Federation",]. (2012) Rossiiskaia gazeta, no. 5976. December 31. [online] Available at: http://rg.ru/2012/12/30/obrazovanie-dok.html [archived in Web Cite] (accessed 29.06.2014). (In Russ.).

Cherepanov, V. S. (1988) Ekspertnye metody v pedagogike [Expert evaluation methods in pedagogy]. Perm, Perm State Pedagogical Institute Publ. 83 p. (In Russ.).

Shikhova, O. F. (2012) Model' proektirovaniia mnogourovnevykh otsenochnykh sredstv dlia diagnostiki kompetentsii studentov v tekhnicheskom vuze [The design model of multilevel tools for assessing students' competence at polytechnics]. Obrazovanie i nauka, no. 2, pp. 23-31. (In Russ.).

Shikhova, O. F. and Shikhov, Yu. A. (2013) Kvalimetricheskii podkhod k diagnostike kompetentsii vypusknikov vysshei shkoly [A qualimetric approach to diagnosing the competences of university graduates]. Obrazovanie i nauka, no. 4, pp. 40-57. (In Russ.). 
Key competences for adult learning professionals: Contribution to the development of a reference framework of key competences for adult learning professionals. Final report (2010) / B. J. Buiskool, S. D. Broek, J. A. van Lakerveld, G. K. Zarifis and M. Osborne. Grundtvig International Network of Course Organisers [online] Available at: http://ginconet.eu/sites/default/files/Key_Competences_For_Adult_Educators.pdf [archived in WebCite] (accessed 29.06.2014).

Submission date: 9.07.2014.

Красавина Юлия Витальевна - старший преподаватель кафедры английского языка, соискатель степени кандидата педагогических наук кафедры профессиональной педагогики Ижевского государственного технического университета им. М. Т. Калашникова. Адрес: 426069, Россия, Удмуртская Республика, г. Ижевск, ул. Студенческая, д. 7. Тел.: +7 (3412) 77-60-55, доб. 72-75; +7 (3412) 77-60-55, доб. 23-74. Эл. адрес: juliadamask@yandex.ru. Научный руководитель — д-р пед. наук, проф. О. Ф. Шихова.

Krasavina Yulia Vitalievna, Senior Lecturer, Department of English; Applicant for the Degree of Candidate of Pedagogy, Department of Vocational Pedagogy, M. T. Kalashnikov Izhevsk State Technical University. Postal address: 7 Studencheskaya St., 426069 Izhevsk, the Udmurt Republic, Russian Federation. Tel.: +7 (3412) 77-60-55, ext.72-75; +7 (3412) 77-60-55, ext.23-74. E-mail: juliadamask@ yandex.ru. Research advisor: Doctor of Pedagogy, Professor O. F. Shikhova. 